\title{
A charging management-based intelligent control strategy for extended-range electric vehicles*
}

\author{
Wen SONG ${ }^{1}$, Xin ZHANG ${ }^{\dagger 1}$, Yi TIAN ${ }^{2}$, Li-he XI ${ }^{1}$ \\ $\left({ }^{1}\right.$ Beijing Key Laboratory of Powertrain for New Energy Vehicles, School of Mechanical, Electronic and Control Engineering, \\ Beijing Jiaotong University, Beijing 100044, China) \\ $\left({ }^{2}\right.$ Department of Mechanical Engineering, The Academy of Armored Forces Engineering, Beijing 100072, China) \\ ${ }^{\dagger}$ E-mail: zhangxin@bjtu.edu.cn
}

Received Jan. 26, 2016; Revision accepted Sept. 26, 2016; Crosschecked Oct. 10, 2016

\begin{abstract}
To fully take advantage of external charging conditions and reduce fuel consumption for extended-range electric vehicles, a charging management-based intelligent control strategy is proposed. The intelligent control strategy is applied to different driving patterns based on the various characteristics of urban roads. When the vehicle is driving on arterial roads, a constant power control strategy is applied. When the driver decides to go to a charging station, the extender-off time can be determined based on the current state of the vehicle and the distance to the charging station. When the vehicle is driving on an expressway, a power follower control strategy is applied. The range-extender engine is controlled to work over a wide variety of regions to obtain optimum fuel economy. The simulation results indicate that as the vehicle arrives at the charging station, the proposed charging management-based intelligent control strategy has made the state of charge reach the lowest permissible level after the driver made the decision to charge at the charging station. Therefore, the driver can charge the vehicle with as much clean electric energy as possible from the charging station.
\end{abstract}

Key words: Recognition of running state, Incremental algorithm, Parallel computing, Electric vehicle http://dx.doi.org/10.1631/jzus.A1600036

CLC number: U469.72

\section{Introduction}

Huge demands in the vehicle market and the increasing deterioration of the environment have become important issues within the domain of sustainable urban development in China. As an important tool for energy conservation and emission reductions in the field of transportation, electric vehicles have been widely promoted by governments all around the world (Al-Alawi and Bradley, 2013; Liang et al., 2013; Malikopoulos, 2014; Zhang $\mathrm{Hu}$ et al., 2014;

\footnotetext{
ॠ Corresponding author

* Project supported by the National Key Technology Support Program of China (No. 2015BAG05B01)

(iD) ORCID: Wen SONG, http://orcid.org/0000-0003-0714-6275

(C) Zhejiang University and Springer-Verlag Berlin Heidelberg 2016
}

Zhang and Xiong, 2015). Compared with electric vehicles, extended-range electric vehicles (E-REVs) not only have the advantage of "zero fuel consumption and zero emissions", but they can also effectively solve the problem of inadequate driving range due to limitations in battery storage power (Sun et al., 2007; Matthe et al., 2011; Zhou et al., 2011; Millo et al., 2013). When an E-REV reaches the charging station, the clean and cheap electricity at the charging station can be stored in the battery, which can then be fully released during driving. Thus, E-REVs can effectively reduce the use of fossil fuels. The charging of an E-REV must be carefully managed to obtain optimal energy storage space for the electricity from the charging station. Current vehicle control strategies for E-REVs are focused on how to use the range-extender to improve vehicle performance in terms of energy 
conservation and emissions reduction. Studies on how to improve vehicle storage capacity for access to clean energy from the charging station are rare (Zhang and Yang, 2011; Qu et al., 2013; Zhang Hong et al., 2014; Zhang et al., 2015).

A charging management-based intelligent control strategy for E-REVs is proposed, which combines the current driving cycle, vehicle running status, distance from the charging station, and other information. The state of charge (SOC) can drop to the desired charging range by the time the E-REV reaches the charging station by reasonable adjustment of the vehicle-demanded power distribution between the range-extender and the battery. Thus, this system can improve the ability of the battery to get electric power from the vehicle charging station.

\section{Influence-factor analysis of E-REV control strategies}

\subsection{Analysis of charging characteristics}

Usually, the E-REV consumes the battery power at the beginning of the route. When the battery cannot meet the need for vehicle power, the range-extender will run and the vehicle will transit into rangeextender mode. Then, the vehicle will be charged at a charging station. The entire driving cycle is shown in Fig. 1, which can be described as a battery charging cycle encompassing "pure electric driving $\rightarrow$ extended range $\rightarrow$ charging from outlet $\rightarrow$ pure electric driving".

In each cycle, the E-REV power consumption equation is shown as

$$
E_{\text {req }}=E_{\text {bat }}+\eta_{\text {eng }} E_{\text {eng }}
$$

where $E_{\text {bat }}$ is the battery output power, $\eta_{\text {eng }}$ is the efficiency of the extended-range, $E_{\text {eng }}$ is the output energy of the range-extender, and $E_{\text {req }}$ is the energy requirement of the vehicle. To improve fuel economy, the efficiency of the range-extender should be improved or the use of the range-extender should be reduced. It is preferable to use electricity from the battery, and the battery needs to have the ability to recharge more clean energy. The electricity storage capacity of the battery is constant. After the end of each charging cycle, the released amount of stored electricity from the battery will affect the vehicle's ability to obtain more clean energy from the charging station in the next cycle. The SOC can reflect the quantity of power in the battery. If the SOC is close to the minimum value, it indicates that electric power is exhausted. Additionally, much electric power can be stored in the battery.

To summarize, total power can be reduced in two ways:

(1) To make full use of the battery power, the SOC is reduced to the desired charge range by the time the vehicle arrives at the charging station.

(2) The efficiency of the range-extender should be improved, i.e., the range-extender engine should work within the optimum fuel consumption region.

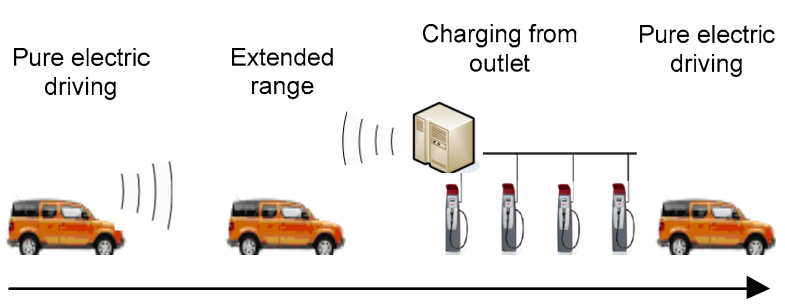

Fig. 1 Schematic diagram for the E-REV driving cycle

\subsection{Analysis of a typical road driving cycle}

The E-REV is mainly used in the city. Its driving performance is affected by the urban driving cycle. Most city roads are divided into four main categories, namely, expressways, arterial roads, secondary roads, and access roads. Table 1 shows a statistical analysis of arterial roads and the expressway driving cycle in Shanghai, Wuhan, and Guangzhou in China. It can be seen that the characteristics of arterial roads and expressways in the same city are significantly different. Maximum speeds and average speeds for arterial roads are relatively slow compared with the expressways in the three cities. This indicates that the road conditions for arterial roads are more congested and the power demands are lower.

Therefore, the operation of the range-extender should be optimized to account for these differences when the E-REV runs on different types of roads during extended-range mode. 
Table 1 Velocity data table for driving cycles for urban arterial roads and expressways

\begin{tabular}{llcc}
\hline \multicolumn{1}{c}{ City } & Road type & $\begin{array}{c}\text { Max. speed } \\
(\mathrm{km} / \mathrm{h})\end{array}$ & $\begin{array}{c}\text { Mean speed } \\
(\mathrm{km} / \mathrm{h})\end{array}$ \\
\hline Shanghai & Arterial road & 57.0 & 17.1 \\
& Expressway & 79.9 & 57.7 \\
Guangzhou & Arterial road & 60.2 & 21.7 \\
& Expressway & 79.8 & 39.5 \\
Wuhan & Arterial road & 59.6 & 28.6 \\
& Expressway & 79.9 & 38.5 \\
\hline
\end{tabular}

\section{E-REV vehicle model}

\subsection{E-REV dynamic system structure}

A domestic extended-range electric vehicle is taken as the object of analysis. Its main structures are shown in Fig. 2. The range-extender is comprised of the engine and the generator. The range-extender and battery provide electric power through the power converter for the driving motor. The basic parameters of the power system components are shown in Table 2.

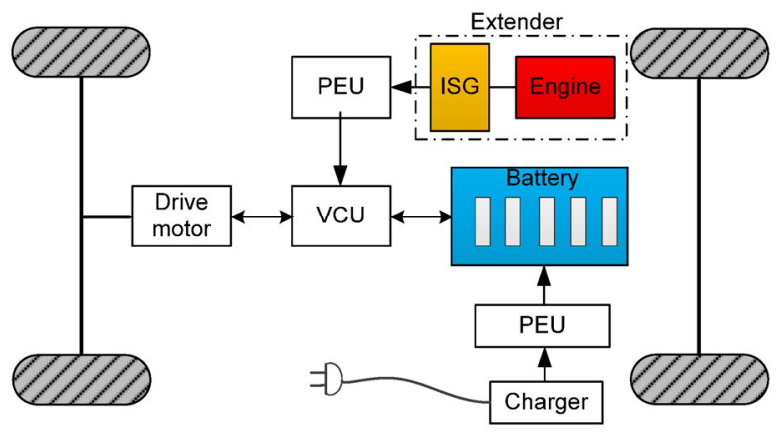

Fig. 2 E-REV power system structure

PEU is the power electric unit; ISG is the integrated starter and generator; VCU is the vehicle control unit

Table 2 Basic parameters of the E-REV

\begin{tabular}{llc}
\hline $\begin{array}{l}\text { Powertrain } \\
\text { component }\end{array}$ & \multicolumn{1}{c}{ Parameter } & Value \\
\hline Vehicle & Curb weight & $1400 \mathrm{~kg}$ \\
& Full mass & $1775 \mathrm{~kg}$ \\
Battery & Lithium battery & $60 \mathrm{~A} \cdot \mathrm{h} / 320 \mathrm{~V}$ \\
& SOC available range & $30 \%-100 \%$ \\
Motor & Motor rated power & $30 \mathrm{~kW}$ \\
& Maximum motor power & $53 \mathrm{~kW}$ \\
Engine & Maximum speed & $4000 \mathrm{r} / \mathrm{min}$ \\
& Displacement & $0.8 \mathrm{~L}$ \\
Final drive & Fixed gear ratio & 7.793 \\
\hline
\end{tabular}

A vehicle simulation model is built using the AVL Cruise simulation tool according to an E-REV powertrain structure (Fig. 3).

The model takes the driving cycle as an import and the driver module will manipulate the accelerator or brake pedal. The control strategy is built in Matlab/ Simulink and it can exchange data with Cruise through the application program interface (Wang et al., 2009).

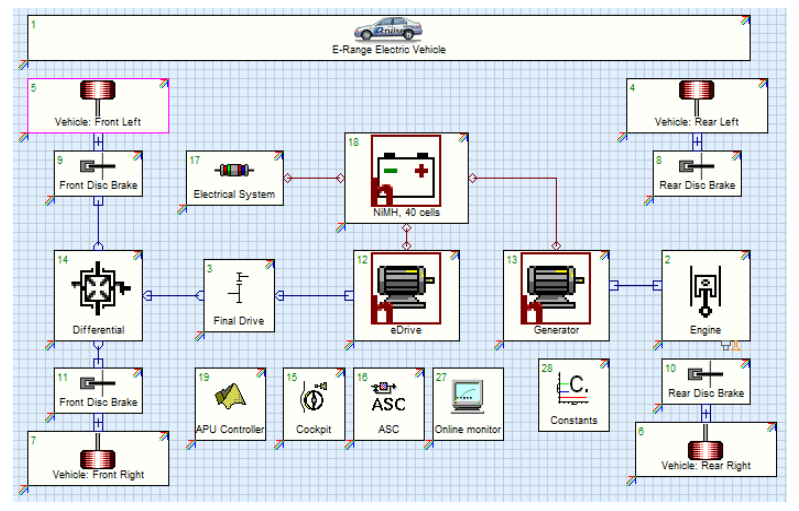

Fig. 3 E-REV model in AVL Cruise

\subsection{Construction of the vehicle road driving and simulation cycle}

The Shanghai electric car arterial road and expressway from Xie (2004) is used as the standard driving cycle in this study. During the simulation, the above-mentioned expressway and arterial road are the basic driving cycles, with 18 times expressway and 25 times arterial road in the basic driving cycle selected, combined into a total of $197.5 \mathrm{~km}$ of vehicle simulation in the driving cycle: the combinations are shown in Fig. 4. The statistical parameters for the simulation of the driving cycle are shown in Table 3.

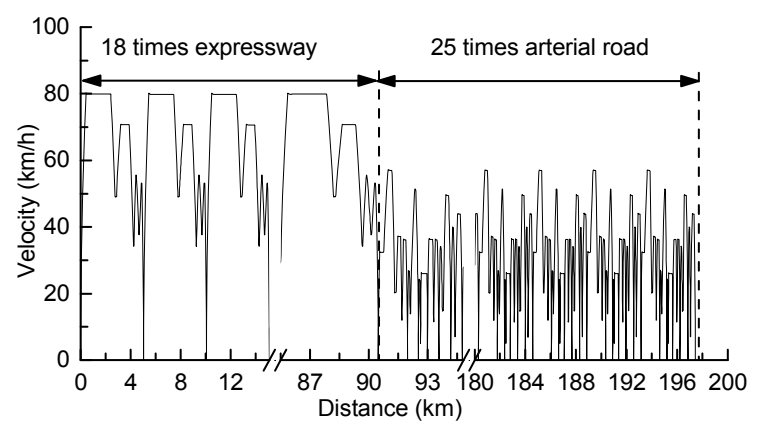

Fig. 4 Simulation of driving cycle curve 
Table 3 Simulation of driving cycle datasheets

\begin{tabular}{lc}
\hline \multicolumn{1}{c}{ Parameter } & Value \\
\hline Expressway $(\mathrm{km})$ & 90.5 \\
Arterial road $(\mathrm{km})$ & 107 \\
Distance $(\mathrm{km})$ & 197.5 \\
Travel time $(\mathrm{s})$ & 28262 \\
\hline
\end{tabular}

\subsection{Simulation and analysis of initial strategy}

In this study, the original strategy is the constant power control strategy. The strategy uses the SOC value as the only threshold to determine the start/stop of the range-extender (Kim et al., 2014). When the $\mathrm{SOC}$ is lower than the preset lower limit, the rangeextender is started instantaneously and works at fixed working point. As the SOC moves above the preset limit, the range-extender turns off. Since there is no mechanical connection between the range-extender and the wheel, the range-extender can continuously work at a certain point on the engine fuel map. In order to not only give the E-REV good fuel economy, but also ensure its dynamic performance, the original strategy usually selects the maximum power point in the high-efficiency engine working area as the constant power working point. In the initial strategy, the chosen operating point, which is called A, is shown in Fig. 5, where BSFC is the brake specific fuel consumption.

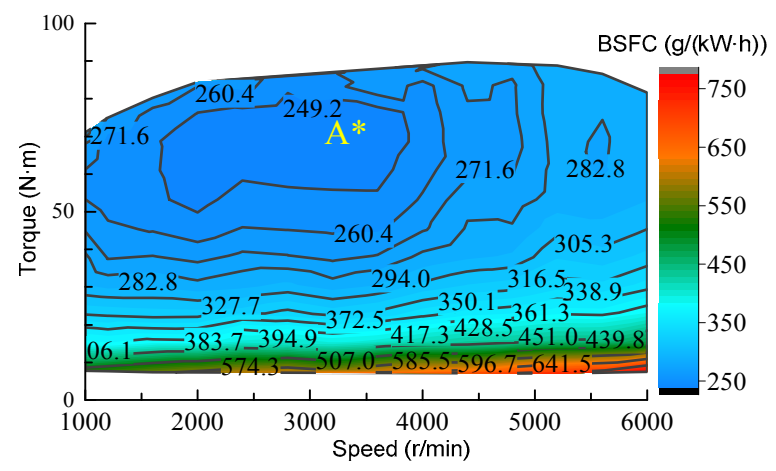

Fig. 5 Engine fuel consumption map

The initial strategy is simulated using the driving cycle simulation established in Section 2.2. There is a charging station at the end of the driving cycle (at $197.5 \mathrm{~km}$ ), while the initial value of the SOC is $90 \%$, the upper limit is $70 \%$, and the lower limit is $30 \%$. The simulation results are shown in Fig. 6.

The output power of the range-extender and the SOC curve for the initial strategy are shown in Fig. 6.
When the SOC reaches the minimum value, the range-extender turns on and its output power is a constant value. Because the driver decides to go to the charging station at $172.5 \mathrm{~km}$ into the route, the initial strategy keeps the SOC rising to the highest value before the range-extender turns off. When the E-REV arrives at the charging station, the SOC value is $52 \%$. Due to the higher SOC, too much energy remains in the battery. Thus, the ability to obtain more clean electricity from the charging station for the E-REV is limited.

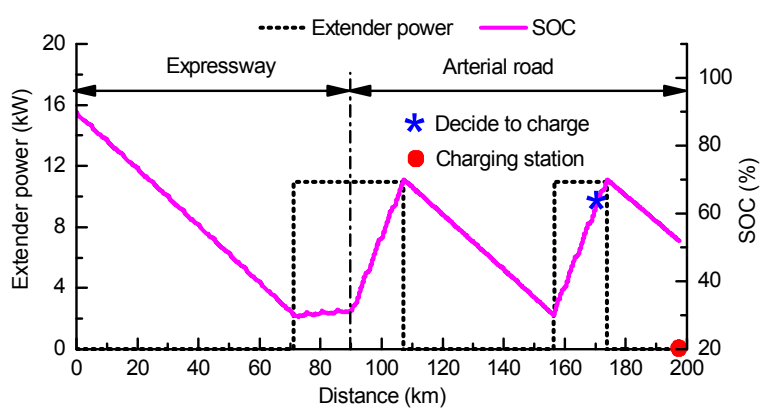

Fig. 6 Initial strategy simulation results

\section{Charging management-based intelligent control strategy}

Based on the above issues, an E-REV charging management-based intelligent control strategy is proposed. The intelligent strategy guarantees that the SOC is reduced to the ideal charging range by the time the vehicle reaches the charging station.

\subsection{Building the control strategy}

When the E-REV is driving on arterial roads under range-extended mode, the fuel economy is poor if the range-extender output power changes following the power demand of the drive motor, as well as its operating point which is located in the low load region of the engine output power map. When the E-REV is operated under a constant power control strategy, higher fuel economy can be reached by adjusting the operating point of the range-extender, and the surplus power can charge the battery. When the E-REV is driving on the expressway under rangeextended mode, the power demand variation covers a wide range if the power follower control strategy is used. It can distribute the engine working points over 
a wide range covering the optimum fuel consumption area, rather than a fixed operating point, and the power demand is entirely provided by the rangeextender. While the electric car needs to replenish energy at a charging station, in order to reduce the SOC to within the desired range at the end of the route, reasonable planning and energy management control for the range-extender and battery power are needed. When the E-REV is driving on the expressway to the charging station, the power demand for the electric vehicle mainly comes from the output power of the range-extender, and the battery is rarely involved in vehicle driving, so the vehicle's SOC changes much less. Therefore, before the rangeextender is started, the SOC value should first be dropped to the desired value. When the E-REV is driving on arterial roads to the charging station, the range-extender outputs constant power. The rangeextender has a large surplus power to charge the battery, and the SOC can be significantly increased, although the best turn-off time for the range-extender should be decided through an intelligent control strategy. A flow chart demonstrates the intelligent control strategy in Fig. 7.

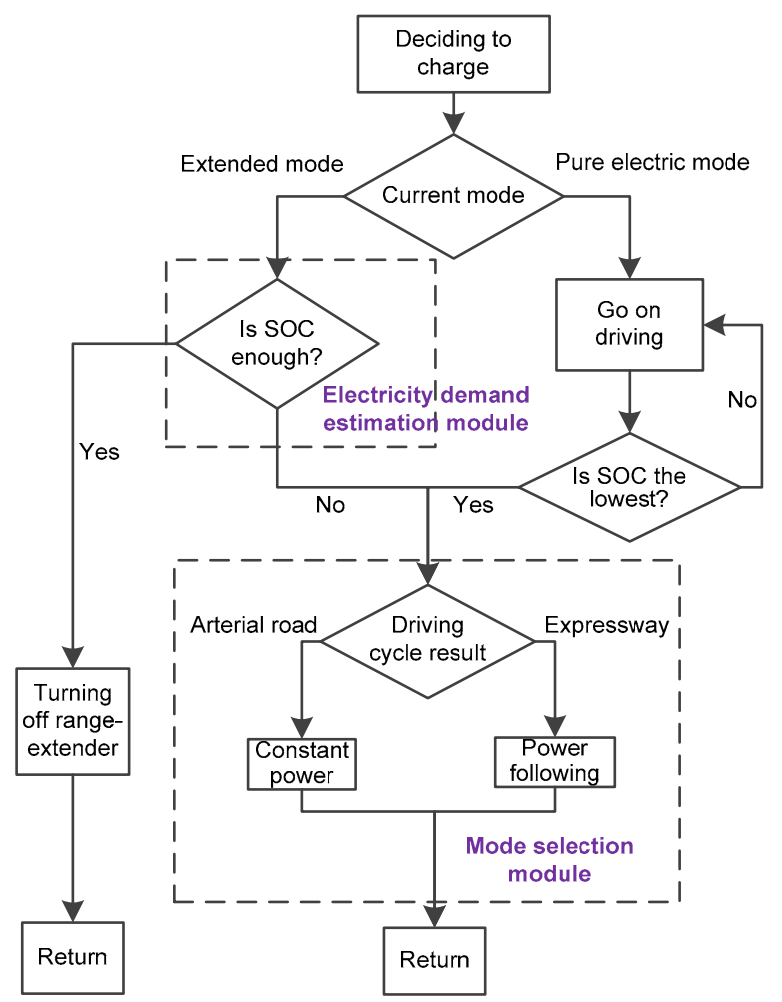

Fig. 7 Control strategy framework diagram

\subsection{Electricity demand estimation module}

When the E-REV is running and the driver decides to enter the charging station, the remaining electric power identification module for the battery based on the current SOC value and the driving cycle is used to determine the range-extender turn-off time.

Suppose the driver decides to enter the charging station and the SOC value demanded is $\mathrm{SOC}_{\mathrm{d}_{-} \text {need, }}$ thus,

$$
\mathrm{SOC}_{\mathrm{d} \_ \text {need }}=d_{\text {vel }} \mathrm{SOC}_{\mathrm{d} \_ \text {avg }},
$$

where $\mathrm{SOC}_{\mathrm{d} \_ \text {avg }}$ is the SOC consumed for the driving distance, and $d_{\text {vel }}$ is the current distance between the E-REV and the charging station, which can be obtained from the global positioning system (GPS) and geographic information system (GIS).

$\mathrm{SOC}_{\mathrm{d}_{-} \text {avg }}$ is closely related to the drive motor output power, which is influenced by the automobile driving cycle. The E-REV actual driving cycle randomly varies with traffic signals, road conditions, weather conditions, driving habits, and other factors. Using a linear fitting method to fit the relationship between $\mathrm{SOC}_{\mathrm{d} \_ \text {avg }}$ and the drive motor average output power $P_{\mathrm{m} \_ \text {avg }}$ which drives in pure electric operating mode, the $\mathrm{SOC}_{\mathrm{d} \_ \text {avg }}$ is

$$
\mathrm{SOC}_{\mathrm{d} \_ \text {avg }}=k_{\mathrm{m}} P_{\mathrm{m} \_ \text {avg }}+b_{\mathrm{m}},
$$

where $k_{\mathrm{m}}$ and $b_{\mathrm{m}}$ are empirical parameters. The equation of $P_{\mathrm{m} \_ \text {avg }}$ is

$$
P_{\mathrm{m} \_ \text {avg }}=\frac{E_{\mathrm{bat}}}{t_{\mathrm{p}}}=\frac{\int_{0}^{t_{\mathrm{p}}} P_{\mathrm{m}} \mathrm{d} t}{t_{\mathrm{p}}},
$$

where $E_{\text {bat }}$ is the battery output energy during the driving time $\left[0, t_{\mathrm{p}}\right]$, and $P_{\mathrm{m}}$ is the driving motor instantaneous output power. Through the method above, the energy that is required for the vehicle to drive to the charging station in pure electric mode can be obtained.

\subsection{Mode selection module for the range-extender}

When the vehicle runs on arterial roads, a constant power control strategy is used. The selection of the constant power operating point of the 
range-extender will directly affect the change rule for the SOC and the start time of the range-extender. While the constant power point of the range-extender is selected as the maximum power point for the optimal fuel consumption area, there is plenty of power remaining for battery charging and the SOC increases rapidly. Under the same driving range, the startup times of the range-extender will increase. Thus, the operating point of the range-extender is selected in the engine optimal fuel consumption area and its output power is less than the initial strategy, which is called $\mathrm{B}$ in Fig. 8.

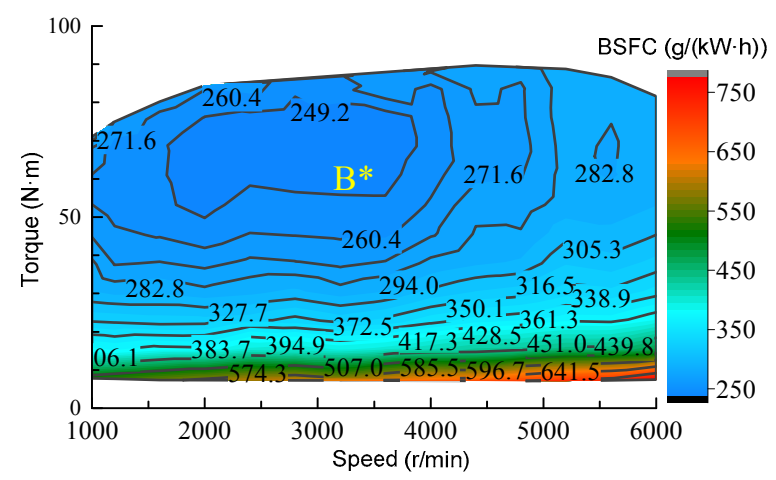

Fig. 8 Engine fuel consumption map

When the vehicle runs on the expressway, the power following control strategy is used. The engine output power $\tilde{P}_{\mathrm{e}}$, which is suitable for fast road operating conditions, is determined by the following method:

$$
\tilde{P}_{\mathrm{e}}=\left[1+\frac{\tilde{\alpha}\left(\mathrm{SOC}_{\mathrm{avg}}-\mathrm{SOC}_{\mathrm{qw}}\right)}{\mathrm{SOC}_{\mathrm{qw}}}\right] P_{\text {req }},
$$

where $P_{\text {req }}$ denotes the current power demanded of the vehicle, $\tilde{\alpha}$ is an empirical parameter, $\mathrm{SOC}_{\mathrm{avg}}$ denotes the average value of the SOC over a period of time, and $\mathrm{SOC}_{\mathrm{qw}}$ denotes the optimal charging expectation parameter.

$\mathrm{SOC}_{\mathrm{avg}}$ is displayed as

$$
\mathrm{SOC}_{\mathrm{avg}}=\frac{\int_{0}^{t_{\mathrm{p}}} \mathrm{SOCd} t}{t_{\mathrm{p}}} .
$$

$\mathrm{SOC}_{\mathrm{qw}}$ is displayed as

$$
\mathrm{SOC}_{\mathrm{qw}}=\frac{d_{\mathrm{vel}}\left(\mathrm{SOC}_{\mathrm{s}}-\mathrm{SOC}_{\mathrm{e}}^{\text {best }}\right)}{d_{\mathrm{v} \_ \text {ch }}}+\mathrm{SOC}_{\mathrm{e}}^{\text {best }}
$$

where $d_{\mathrm{v} \_ \text {ch }}$ denotes the distance between the E-REV and the charging station when the driver chooses to charge, $\mathrm{SOC}_{\mathrm{s}}$ denotes the $\mathrm{SOC}$ value when the driver chooses to charge, and $\mathrm{SOC}_{\mathrm{e}}^{\text {best }}$ denotes the ideal value for the SOC when the E-REV reaches the charging station.

\section{Analysis of the simulation results for the charging management-based intelligent con- trol strategy}

Fig. 9 shows the output power of the rangeextender and the change rule curve of the SOC under the intelligent control strategy. When the vehicle runs on the expressway, the SOC value reaches its lowest point for the first time. Then the range-extender is turned on, its output power follows the power demand, and the SOC value changes slowly. When the vehicle runs on arterial roads, the SOC drops to the lowest value again. Then the range-extender is turned on and maintains constant output power. When the driver decides to charge in the charging station, the SOC increases to a certain value and then the range-extender is turned off, and the vehicle then is running in pure electric mode to the charging station.

From Sections 3 and 4, the intelligent control strategy operates the range-extender in different modes according to the current driving cycle by using the power following control strategy on the expressway, and a constant power control strategy on arterial roads. When the driver decides to enter the charging station $172.5 \mathrm{~km}$ into the route, the range-extender keeps charging the battery. When the intelligent control strategy evaluates that there is enough electric power in the battery for driving, it turns off the range-extender and keeps the vehicle running to the charging station in pure electric mode. As the vehicle reaches the charging station, the SOC drops to $32.8 \%$. Compared with the simulation results in Sections 2 and 3, it declines $14.2 \%$, and it guarantees the SOC is in the ideal charge range when the vehicle reaches the charging station. 
Meanwhile, two different initial SOC values and two different charging intentions are simulated and calculated, respectively, for the designated driving cycle. The SOC value for the vehicle to the charging station is compared, respectively, in the cases using the intelligent control strategy and the initial strategy, and the simulation results are shown in Table 4. It can be seen that the SOC value for the E-REV is maintained in the vicinity of $32 \%$ through the intelligent control strategy, while the SOC value is about $52 \%$ using the initial strategy. Therefore, the intelligent control strategy proposed in this study can enable the battery to obtain more clean electricity from the charging station, and reduce the use of fossil fuels in the journey.

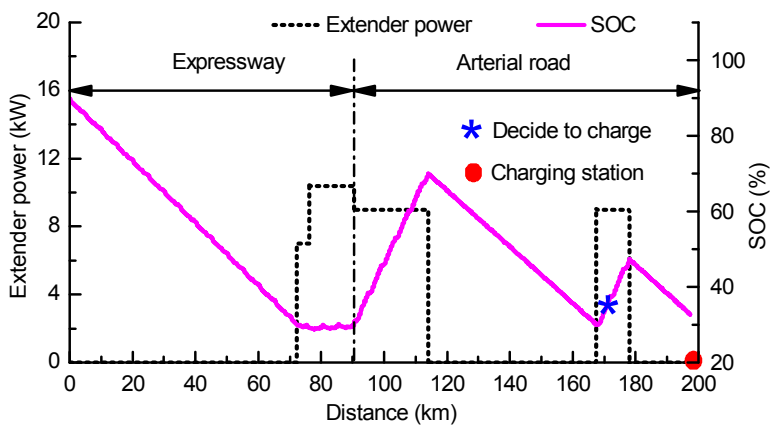

Fig. 9 Simulation results for the charging managementbased intelligent control strategy

Table 4 Simulation results

\begin{tabular}{cccc}
\hline Strategy & $\begin{array}{c}\text { Initial } \\
\text { SOC } \\
(\%)\end{array}$ & $\begin{array}{c}\text { Distance to } \\
\text { the charging } \\
\text { station (km) }\end{array}$ & $\begin{array}{c}\text { SOC when } \\
\text { arriving at the } \\
\text { charging sta- } \\
\text { tion (\%) }\end{array}$ \\
\hline $\begin{array}{c}\text { Original } \\
\text { control } \\
\text { strategy }\end{array}$ & 90 & 25 & 52.0 \\
\hline Intelligent & 60 & 25 & 52.3 \\
control & 90 & 40 & 32.7 \\
strategy & 60 & 40 & 32.8 \\
& & 25 & 32.1 \\
\end{tabular}

\section{Conclusions}

The use characteristics for an E-REV on urban roads are analyzed to determine its working mode under different operating conditions. An intelligent control strategy for an E-REV is proposed. The elec- tric power demands of the battery estimation module are developed. According to this strategy, when the vehicle runs on arterial roads, a constant power control strategy is used, while on expressways, a power following control strategy is used.

The simulation results indicate that the proposed intelligent control strategy, compared with the initial strategy, can reasonably optimize the working mode of the extender according to the current operating conditions of the vehicle. When the driver decides to charge in the charging station, the system can determine the best turn-off time of the extender according to the value of the SOC. Thus, by the time the charging station is reached, the SOC value can be reduced to the ideal charge range. The system can improve the ability of the battery to obtain clean electricity from the charging station.

\section{References}

Al-Alawi, B.M., Bradley, T.H., 2013. Review of hybrid, plug-in hybrid, and electric vehicle market modeling studies. Renewable \& Sustainable Energy Reviews, 21: 190-203. http://dx.doi.org/10.1016/j.rser.2012.12.048

Kim, M., Jung, D., Min, K., 2014. Hybrid thermostat strategy for enhancing fuel economy of series hybrid intracity bus. IEEE Transactions on Vehicular Technology, 63(8): 3569-3579. http://dx.doi.org/10.1109/TVT.2013.2290700

Liang, J.Y., Zhang, J.L., Zhang, X., et al., 2013. Energy management strategy for a parallel hybrid electric vehicle equipped with a battery/ultra-capacitor hybrid energy storage system. Journal of Zhejiang University-SCIENCE A (Applied Physics \& Engineering), 14(8):535-553. http://dx.doi.org/10.1631/jzus.A1300068

Malikopoulos, A.A., 2014. Supervisory power management control algorithms for hybrid electric vehicles: a survey. IEEE Transactions on Intelligent Transportation Systems, 15(5):1869-1885. http://dx.doi.org/10.1109/TITS.2014.2309674

Matthe, R., Turner, L., Mettlach, H., 2011. Voltec battery system for electric vehicle with extended range. SAE International Journal of Engines, 4(1):1944-1962. http://dx.doi.org/10.4271/2011-01-1373

Millo, F., Rolando, L., Mallamo, F., et al., 2013. Development of an optimal strategy for the energy management of a range-extended electric vehicle with additional noise, vibration and harshness constraints. Proceedings of the Institution of Mechanical Engineers, Part D: Journal of Automobile Engineering, 227(1):4-16. http://dx.doi.org/10.1177/0954407012457488

Qu, X.D., Wang, Q.N., Yu, Y.B., 2013. A study on the control strategy for APU in an extended-range EV. Automotive 
Engineering, 35(9):763-768 (in Chinese).

Sun, F.C., Shen, T.Q., Cheng, X.M., et al., 2007. Identification for the auxiliary power unit in a hybrid electric vehicle. Transactions of Beijing Institute of Technology, 27(9): 787-791 (in Chinese). http://dx.doi.org/10.15918/j.tbit1001-0645.2007.09.007

Wang, Q.N., Yu, Y.T., Zeng, X.H., et al., 2009. Development of forward-looking simulation platform for hybrid electric vehicle based on software Cruise. Journal of Jilin University (Engineering and Technology Edition), 39(6): 1413-1419 (in Chinese). http://dx.doi.org/10.13229/j.cnki.jdxbgxb2009.06.016

Xie, F., 2004. Electric Vehicle Road Driving Cycle. Research Report, China Automotive Engineering Research Institute, Chongqing, China (in Chinese).

Zhang, C.N., Zhou, W., Li, J.Q., et al., 2015. An online energy management strategy for extended range electric vehicles based on Pontryagin's minimum principle. Transactions of Beijing Institute of Technology, 35(9):931-935 (in Chinese). http://dx.doi.org/10.15918/j.tbit1001-0645.2015.09.010

Zhang, Hong, He, Z., Wang, Y., 2014. Control strategy research of auxiliary power unit in range-extended electric bus. Transportation Electrification Asia-Pacific (ITEC Asia-Pacific), IEEE Conference and Expo, IEEE. http://dx.doi.org/10.1109/ITEC-AP.2014.6940739

Zhang, Hu, Wang, C.L., Zhang, Y., et al., 2014. Drivability improvements for a single-motor parallel hybrid electric vehicle using robust controls. Journal of Zhejiang University-SCIENCE A (Applied Physics \& Engineering), 15(4):291-301. http://dx.doi.org/10.1631/jzus.A1300356

Zhang, S., Xiong, R., 2015. Adaptive energy management of a plug-in hybrid electric vehicle based on driving pattern recognition and dynamic programming. Applied Energy, 155:68-78.

http://dx.doi.org/10.1016/j.apenergy.2015.06.003

Zhang, X., Yang, X.P., 2011. Sliding mode control of powertrain for SHEV with a desired battery charging curve set.
Automotive Engineering, 33(4):352-356 (in Chinese).

Zhou, S., Niu, J., Chen, F.A., 2011. A study on powertrain design and simulation for range-extended electric vehicle. Automotive Engineering, 33(11):924-929 (in Chinese).

\section{中文概要}

题 目: 增程式电动汽车智能充电管理控制策略研究

目 的: 为了充分利用外界充电条件, 减少现有增程式电 动汽车燃油消耗, 结合当前运行工况、整车运行 状态以及相距充电站距离等信息, 通过合理调整 整车需求功率在增程器与动力电池之间的分配, 使得增程式电动汽车在到达充电站时荷电状态 (SOC) 降低到理想充电范围, 提高了整车从充 电站获取清洁电能的效率。

创新点: 1 . 根据车辆当前状态, 建立电池需求电量估算模 块和增程器输出功率计算模块; 2 . 在司机决定进 入充电站充电后, 控制电池 SOC 在车辆进入充电 站时降到最低。

方 法: 1. 通过对使用环境进行分析, 建立智能控制策略, 在不同的运行工况下对增程器采用不同的控制 方式。通过理论推导, 建立动力电池需求电量估 算模块 (公式 2); 2. 通过仿真计算, 将所提出的 智能控制策略与初始控制策略进行对比。

结 论: 1 . 与整车原策略相比, 本文提出的智能控制策略 能够根据车辆当前运行工况, 控制增程器采用不 同的工作方式；2. 在司机决定到充电站充电时, 根据当前 SOC 值, 确定最佳增程器关闭时刻, 可 使增程式电动汽车在到达充电站时, SOC 降低到 理想充电范围, 提高动力电池从充电站获取清洁 电能的能力。

关键词: 运行状态识别; 增量算法; 并行计算; 电动汽车 